\title{
A Mixed Method Analysis of Burnout and Turnover Intentions Among Higher Education Professionals During COVID-19
}

\author{
Jake D. Winfield and Joseph H. Paris \\ Department of Policy, Organizational and Leadership Studies \\ Temple University, Philadelphia, Pennsylvania, United States
}

March, 2022

\begin{abstract}
The COVID-19 pandemic rapidly and dramatically altered higher education including changes to the workplace. Many staff and faculty positions were eliminated while other employees experienced furloughs or reduced work hours. Our study examines the experiences of 1,080 higher education professionals serving in various functional roles during the COVID-19 pandemic from 830 institutions of higher education in the United States. We utilized an explanatory sequential mixed methods research design to examine quantitative and qualitative survey data from October 2020 to understand how jobs in higher education changed during the pandemic and how these changes were associated with an individual's burnout and intention to leave higher education. Using multiple regression and thematic analysis and the job-demands and resources framework, we find that higher education professionals who experienced significant disruption in their work had increased odds of experiencing burnout. We also find that eliminating staff positions and significant levels of burnout were associated with increased intentions to leave their current profession in higher education. In open ended responses, higher education professionals described how increased job demands through decreased staff and increased workloads were not accompanied with increased resources, leading to burnout. These working conditions negatively affected participants' personal lives, including their physical and mental health. We conclude with recommendations for research on working conditions in higher education in the pandemic-era and emphasize that institutional leaders should seek systemic changes to support employees.
\end{abstract}

Keywords: burnout, turnover, higher education, job demands and resources, explanatory sequential mixed methods design, ordinal regression, logistic regression, thematic analysis

Corresponding author: Jake Winfield (jakewinfield@temple.edu)

Author's note: The citation for the version of record, published in the Journal of Education Human Resources, is below. Please cite the version of record.

Winfield, J. D. \& Paris, J. H. (2022). A mixed method analysis of burnout and turnover intentions among higher education professionals during COVID-19. Journal of Education Human Resources. Advance online publication. https://doi.org/10.3138/jehr2021-0048 
"We have broken the backs of the staff who were the last line of defense." - Higher Education Professional, October 2020

The COVID-19 pandemic rapidly and dramatically altered higher education. In early 2020, most higher education institutions transitioned to remote teaching and work (Turk et al., 2020). Institutions eliminated staff and faculty positions, implemented furloughs, or reduced work hours (Bauman, 2021; Chronicle of Higher Education, 2020). Researchers have studied the impact of these conditions on teaching and learning (e.g., Mellieon \& Robinson, 2021; Rapanta et al., 2020), and college students' experiences and well-being (e.g., Marinoni et al., 2020; Molock \& Parchem, 2021; Son et al., 2020). The few studies that have examined the effects of COVID-19 on the experiences of higher education professionals (HEPs) have relied on data from one institution (e.g., Kaleba, 2020; Regehr \& Goel, 2020). Functional areas of higher education such as admissions, student affairs, and registrar offices have historically experienced high rates of employee turnover (Mullen, Malone, et al., 2018), and during the pandemic have been at higher risk of job loss (Bauman, 2021; McGraw et al., 2020). Turnover rates often exceed 50\% for HEPs (Marshall et al., 2016) and turnover is costly for organizations (O’Connell \& Kung, 2007). Thus, it is important to understand the experiences of administrators across numerous institutions and how COVID-19 impacted their working conditions.

In October 2020, the American Association of Collegiate Registrars and Admissions Officers (AACRAO) disseminated a survey (Kilgore, 2020) to HEPs to understand how higher education jobs changed during the pandemic and respondents' burnout and intention to leave higher education. We analyzed these data using an explanatory sequential mixed methods design (Creswell \& Plano Clark, 2018). We conducted multiple regression analyses to estimate the effects of various job demands and resources (Demerouti \& Bakker, 2011) on burnout and 
turnover intention, controlling for institutional characteristics and COVID-19 cases. We find that HEPs who experienced significant disruption in their work had increased odds of experiencing burnout, and that eliminating staff positions and significant levels of burnout were associated with increased turnover intensions. Those findings guided our qualitative, thematic analysis (Ryan \& Bernard, 2003). Respondents described how burnout stemmed from decreased staff and increased workloads. These working conditions negatively affected participants' personal lives including their health and ability to parent children. Recognizing that addressing burnout requires systemic changes (Peterson, 2020) and that self-care rhetoric cannot mitigate the concerns of HEPs (Squire \& Nicolazzo, 2019), we argue that institutional leaders should address long-standing concerns about working conditions to stem a potential exodus of HEPs (Ellis, 2021a; McClure, 2020).

\section{Literature Review}

Burnout has been studied in a variety of contexts (e.g., Maslach, 2003; Schaufeli et al., 2009) and has been associated with decreased job satisfaction among HEPs (Brewer \& Clippard, 2002). The higher education work environment has many characteristics that can exacerbate employee burnout causing emotional exhaustion, depersonalization, and a diminished sense of personal accomplishment (Maslach, 2003). HEPs can face extreme work obligations that contribute to burnout (Marshall et al., 2016; Mullen, Malone, et al., 2018). These obligations require some HEPs to be available outside typical business hours to support students (Wilk, 2016). HEPs who provide student services or are exposed to trauma often have increased levels of burnout (Kunk-Czaplicki, 2021; Mullen, Blount, et al., 2018; Preston et al., 2021). Anderson (2021) highlights how HEPs responsible for promoting diversity, equity, and inclusion experience burnout because of institutional practices that 'burn through' these workers, in part 
because of increased responsibilities and declining resources. These high levels of burnout and stress among HEPs have also been associated with increased turnover intentions (Mullen, Malone, et al., 2018).

Budget cuts in higher education have negative effects on working conditions. Persistent cost-cutting can make lower-level staff feel disillusioned and less willing to find cost-saving measures (Romano et al., 2010). Workforce reductions and furloughs can correspond with increased expectations of individuals at multiple levels of an institution's organizational hierarchy, increasing job-related stress (Pelletier et al., 2015; Romano et al., 2010; Szekeres, 2006). When budget cuts decrease staffing levels, layoff survivors can become disengaged (Li \& Guthrie, 2015). Therefore, decreased staff positions driven by the threat of budget shortfalls during the pandemic may have impacted HEPs' working conditions.

Workplace conditions can have an impact on individuals' personal lives. Recent surveys of HEPs found that the quality of one's work-life is associated with well-being and quality of life, especially for those who may experience compassion fatigue (Chessman, 2021; Mudrak et al., 2018; Preston et al., 2021). Children of student affairs professionals have been shown to internalize 'bad days' their parents have at work, indicating that harm stemming from working conditions may extend beyond HEPs themselves (Lehman \& Krebs, 2018). This research suggests that what happens in the workplace extends into other facets of an individual's life.

The higher education working environment can be stressful for employees, especially in times of instability. We advance research on the higher education workplace by examining how changes in working conditions caused by the COVID-19 pandemic are associated with HEPs' burnout and turnover intentions. Although previous literature has connected burnout to turnover intentions in higher education (Mullen, Malone, et al., 2018), we consider additional aspects of 
the working environment while analyzing data across various functional areas, organizational hierarchies, and institutions.

\section{Theoretical Framework}

We utilized the job demands-resources (JD-R) model of burnout (Demerouti et al., 2001; Demerouti \& Bakker, 2011) as a theoretical framework. Burnout is the result of chronic workplace stress characterized by exhaustion, negative feelings towards one's job, and lack of accomplishment (World Health Organization, 2021). While burnout was originally identified in human services professions, the construct has expanded to any workplace domain (Schaufeli et al., 2009).

The JD-R framework posits that burnout occurs when job demands are high and job resources are low (Demerouti et al., 2001). Job demands are aspects of jobs that require "sustained physical and/or psychological" effort such as high pressure or irregular work hours (Demerouti \& Bakker, 2011, p. 2). Job resources represent aspects of jobs that assist in achieving goals and reduce job demands (Demerouti \& Bakker, 2011). As such, the JD-R framework explicitly considers how an individual is situated within the larger work environment. JD-R has recently been applied to the field of higher education to study the experiences of HEPs (e.g., Kunk-Czaplicki, 2021; Mudrak et al., 2018).

We extend the JD-R framework by interrogating how burnout is related to one's intention to leave higher education. Burnout among HEPs has been associated with lower job satisfaction (Brewer \& Clippard, 2002), lower health quality of life measures (Mudrak et al., 2018; Preston et al., 2021), and increased turnover intentions among student affairs professionals (Mullen, 
Malone, et al., 2018). We utilize the JD-R framework to examine the following research questions:

1. Are job demands and resources statistically significant predictors of HEPs' burnout and turnover intentions when accounting for institutional characteristics and the number of institutionally reported COVID-19 cases?

2. How do HEPs describe experiences of burnout during the COVID-19 pandemic?

\section{Methods}

We utilized a mixed-methods explanatory sequential design (Creswell \& Plano-Clark, 2018) to examine and describe how job demands and resources are associated with HEPs' reported burnout and turnover intentions, and how HEPs described experiences of burnout during the pandemic.

\section{Data Collection and Sample}

In October 2020, AACRAO disseminated a survey (Kilgore, 2020) to members on the impact of COVID-19 on employees' working conditions, changes in workplace responsibilities, and pandemic-related stressors. Survey respondents included 1,411 AACRAO members from 15 countries. We examined responses from HEPs employed in the United States as the pandemic's severity and policy responses vary by country (Marinoni et al., 2020), narrowing our sample to 1,326 respondents. We eliminated 108 respondents who selected more response options than indicated in the survey instructions because this suggested these individuals were not paying close attention (Alvarez et al., 2019). This narrowed our sample to 1,218 respondents. Finally, 138 responses were eliminated using listwise deletion for missing quantitative data. The final analytic sample was 1,080 respondents from 782 institutions. Respondents primarily worked in 
records and registration, enrollment management, or admissions, aligning with the largest areas of responsibility among AACRAO members (AACRAO, n.d.). Of these respondents, 801 (73\%) responded to at least one open-ended survey question. Table 1 includes descriptive statistics of the respondents.

We collected data from the Integrated Postsecondary Education Data System (IPEDS) for the 2019 reporting year (U.S. Department of Education, 2019) for our institutional-level variables and COVID-19 cases on November 5, 2020 from the New York Times database (New York Times, 2021). Of the 1,080 respondents, 830 worked at institutions in the New York Times database, reducing our sample for the analyses that include COVID-19 cases $(M=399.3, M d n=$ $98, S D=764.3$ ). Table 2 includes descriptive statistics of institutional characteristics.

\section{Variables}

Our study includes several variables that reflect job demands and resources that are theoretically associated with burnout and turnover intention. Our predictor variables include organizational proximity to the chief executive (president or chancellor), front-line student service, transition of functions and services, and staffing level changes. Organizational proximity to the chief executive was measured as a categorical variable that reflected the positions between the respondent and the chief executive within the organizational hierarchy. Front-line student service was measured as a dichotomous variable that reflected whether respondents work directly with students. If an individual did not respond to this question, we assumed they are not responsible for front-line student service because AACRAO members and survey respondents predominantly work in functional areas that do not traditionally provide front-line student service (AACRAO, n.d.). Transition of functions and services was a categorical variable that reflected the transition of work to a remote format. These variables represent job demands in the JD-R 
framework as they require sustained effort and skills (Demerouti \& Bakker, 2011). The final predictor variable was staffing level change since March 2020 which reflected no changes in staffing, the elimination of positions, or reduction in work hours/furloughs. We considered this variable a job resource in the JD-R framework (Demerouti \& Bakker, 2011) because it represents a support that may have been available to HEPs.

We included two outcome variables in our analysis: burnout and turnover intention. Respondents were provided with the following definition of burnout: "Burnout is defined as 'when you get to a feeling of exhaustion with life. It's not just physical or psychological exhaustion, it's everything together. But instead of collapsing and saying, 'I can't do this anymore,' you hit a wall and climb over it'” (McClure, 2020, para. 6). Respondents selected from a series of five ordinal responses, as shown in Table 1. We utilized burnout as a predictor of turnover intention and as an outcome predicted by job demands and resources.

The second outcome variable was one's intention to leave their career earlier than they anticipated. Turnover intention was measured with three categorical responses: "Yes, I am considering leaving my profession earlier than anticipated," "Yes, I am more committed to staying in my career," and "No, the last six months have not significantly impacted my career decisions." For our analysis, we recoded these responses into a dichotomous variable that represented whether individuals considered leaving their profession earlier than anticipated. Table 1 includes descriptive statistics for the variables used in our quantitative analyses.

Understanding that institutional characteristics are related to turnover intentions and work environment (Dahlvig \& Beers, 2018; Rosser \& Townsend, 2006), we included institutional control, institution level, and a ratio of full-time equivalent (FTE) student enrollment headcount to FTE staff positions as variables in our models. We included institutionally reported COVID- 
19 cases because job demands may vary based on the pandemic's severity on campus. Given the skewness of the original COVID-19 data, we used log transformation to make the data as "normal" as possible to increase the validity of our quantitative analyses.

\section{Data Analysis}

Following an explanatory sequential mixed methods design (Creswell \& Plano-Clark, 2018), we first analyzed the quantitative data using multiple regression. Guided by those findings, we conducted a thematic analysis of the qualitative data.

\section{Quantitative Analysis}

We examined the survey data and tested whether they met the assumptions associated with ordinal and binary logistic regression (Box \& Tidwell, 1962; Stevens, 2002). We also confirmed that our log transformation of the original COVID-19 data resulted in a log-normal distribution. After ensuring our data met relevant assumptions, we conducted a cumulative odds ordinal logistic regression with proportional odds (Liu \& Koirala, 2012) to examine whether job demands and resources are statistically significant predictors of burnout. Next, we conducted a hierarchical binary logistic regression (Keith, 2015) to investigate whether job demands and resources and burnout are statistically significant predictors of turnover intention. We entered the following sequence of variables into the hierarchical regression model: (1) institutional characteristics, (2) job demands and resources, and (3) burnout. To extend our analyses, we added the natural log of the number of institutionally reported COVID-19 cases as a predictor in both regression models.

\section{Qualitative Analysis}


Following our quantitative analysis, we engaged in thematic analysis (Ryan \& Bernard, 2003) of survey questions that asked respondents how burnout manifested for them and their colleagues and to describe changes in staffing levels within the respondent's unit. We began by in-vivo coding 100 random responses (Saldaña, 2013), creating codes using respondents' words. We included a priori codes from our quantitative findings including staff level changes, transition of services, front-line student service, and organizational proximity to the chief executive. Next, we conducted collaborative axial coding (Saldaña, 2013). We coded the remaining responses using the axial codes and in vivo coding when responses did not align with the axial codes (Saldaña, 2013). We collaboratively reviewed new in vivo codes to create new axial codes every 100 responses. After coding all responses, we engaged in constant comparison between cases (Ryan \& Bernard, 2003), examining how responses varied based on organizational proximity to the chief executive, transition of functions and services, and staff level changes as these were statistically significant variables in at least one of our regression models.

We utilized multiple strategies to ensure trustworthiness in our qualitative analysis. We reflexively engaged with how our own experiences during the pandemic may have informed our analysis (Berger, 2015; Shenton, 2004). Both authors coded 25\% of responses to ensure codes were applied consistently and to create a shared understanding of the data (Shenton, 2004). In frequent meetings, we resolved any disagreements in code applications.

\section{Mixed Methods Analysis}

Integration of quantitative and qualitative data is key to mixed methods research (Creswell \& Plano Clark, 2018). We used a single source of data which is inherently a mixed methods approach (Bazeley, 2006). Additionally, we utilized our quantitative findings to guide 
our qualitative analysis (Bazeley, 2006; Creswell \& Plano Clark, 2018). Finally, we crafted joint displays (Tables 5 and 6 ) to integrate and visually present our findings (Gutterman et al., 2015).

\section{Positionality}

Our positions as scholars, caretakers, and people influenced how we approached this study (Berger, 2015). We both currently teach college students and Joseph Paris previously worked in college admissions. Dr. Paris serves on AACRAO's Research Advisory Board. This relationship helped provide access to the data, but we were not involved in survey design or dissemination. Our employment may have been more secure than many of our respondents, as a graduate student and faculty member. We recognize that as white, male scholars who worked remotely during the pandemic, we were in many ways shielded from harms even though we worked as caretakers of loved ones young and old while social distancing. In our analysis, we consistently centered the humanity of HEPs to understand their experiences, with care for their stories.

\section{Limitations}

We recognize that our data have meaningful limitations as they do not include demographic information. Previous research using the JD-R framework did not include participants' gender, race, or ethnicity (e.g., Demerouti et al., 2001). However, this may not be a justifiable assumption in studying burnout during the pandemic because of disproportionate effects on Communities of Color (Gracia, 2020; Molock \& Parchem, 2021) and women and single parents with increased caretaking responsibilities (Calarco et al., 2021; Power, 2020). Race, ethnicity, and gender have been shown to influence burnout among HEPs as well (Anderson, 2021; Howard-Hamilton et al., 1998; Steele, 2018). However, we believe that our 
findings may be the 'best case' scenario, and women and HEPs of Color may have even greater turnover intentions and burnout than our averages.

\section{Findings}

Our explanatory sequential mixed methods (Creswell \& Plano-Clark, 2018) approach required us to first analyze the quantitative data and then use those findings to guide our analysis of open-ended survey responses. We observed that quantitative questions alone could not capture the variety and intensity of HEPs' experiences amid COVID-19.

\section{Quantitative Findings}

Using multiple regression (Keith, 2015), we investigated two related questions. First, how do job-demands and resources predict burnout, and second, how do job-demands, resources, and burnout predict turnover intention.

\section{Predicting Burnout}

We conducted an ordinal logistic regression to determine the effects of job demands and resources on the reported burnout among HEPs. We determined that there were proportional odds as assessed by a full likelihood ratio test comparing the fitted model to a model with varying location parameters, $\chi^{2}(33)=47.301, p=.051$. The deviance goodness-of-fit test indicated that the model was a good fit to the observed data, $\chi^{2}(4089)=3010.761, p=.736$, but most cells were sparse with zero frequencies in $79.2 \%$ of cells. However, the final model statistically significantly predicted burnout over and above the intercept-only model, $\chi^{2}(11)=$ 36.647, $p<.0005$. The model explained approximately $3.5 \%$ (Nagelkerke $R^{2}=.035$ ) of the variance in reported burnout. 
Among the job demands and resources examined, the transition of functions and services had a statistically significant effect on the prediction of reported burnout, $\chi^{2}(2)=23.347, p<$ .0005 . The odds of those who experienced significant disruption when transitioning remote work reporting significant burnout was 1.713 times that of those who experienced little disruption. This had a statistically significant effect, $\chi^{2}(1)=14.407, p<.0005$. Similarly, the odds of those who were unable to or did not transition remote work reporting burnout was 1.751 times that of those who experienced little disruption. Additionally, while one's proximity to the chief executive was not a statistically significant predictor in the overall model $(p=.079)$, the odds of respondents with positions as a chief executive reporting burnout was reduced by a factor of .614 compared to HEPs at lower levels of the organizational hierarchy, $(p=.047)$. Table 3 summarizes these findings.

Next, we added the number of reported institutional-level COVID-19 cases to the ordinal logistic regression to determine the effects of COVID-19 cases on the prediction of burnout. The model had proportional odds, $\chi^{2}(36)=47.869, p=.089$, and was determined to be a good fit for the data based on the deviance goodness-of-fit test, $\chi^{2}(3100)=2226.943, p=1.000$, but most cells were sparse with zero frequencies $(79.0 \%$ of cells). However, the final model statistically significantly predicted burnout over and above the intercept-only model, $\chi^{2}(12)=38.689, p=$ .000 . The model explained approximately $4.8 \%\left(\right.$ Nagelkerke $\left.R^{2}=.048\right)$ of the variance in reported burnout. The addition of the number of COVID-19 cases to the model contributed approximately $1.3 \%$ to the explanation of variance in reported burnout. However, the COVID-19 variable was not a statistically significant predictor of reported burnout, $p=.232$. Notably, transition of functions and services remained a statistically significant predictor in the overall model, $\chi^{2}(2)=22.540, p=.000$. Table 3 summarizes these findings. 


\section{Predicting Turnover Intention}

We conducted a hierarchical binary logistic regression to examine the effects of job demands and resources and burnout on the prediction of turnover intentions. A Hosmer and Lemeshow Test (2000) indicated that the model was a good fit for the observed data, $\chi^{2}(8)=$ $9.892, p=.273$. The overall model was a statistically significant improvement compared to the base model, $\chi^{2}(15)=124.690, p<.0005$. The model explained approximately $15.5 \%$ (Nagelkerke $R^{2}=.155$ ) of the variance in turnover intention and correctly classified $73.6 \%$ of cases. Sensitivity was $11.7 \%$, specificity was $78.3 \%$, positive predictive value was $60.0 \%$, and negative predictive value was $24.1 \%$.

Among the job demands and resources, only staffing level changes was statistically significant for those employed at institutions at which some staff positions were eliminated, $\chi^{2}(1)$ $=7.923, p=.005$. The odds of those employed at an institution where some staff positions were eliminated reporting an intent to leave their career was 1.713 times that of those employed at an institution where all staff were kept fully employed. Additionally, burnout was a statistically significant predictor of turnover intention among those who reported a "definite sense of burnout," $\chi^{2}(1)=8.622, p=.003$, and a "significant sense of burnout," $\chi^{2}(1)=33.524, p<.0005$. The odds of those with a "definite sense of burnout" and "a significant sense of burnout" reporting an intent to leave their career was 3.221 and 11.035 times that of those who reported "little burnout." Table 4 summarizes findings for the overall model.

Next, we conducted a hierarchical binary logistic regression to examine the effects of job demands and resources, burnout, and the number of reported institutional-level COVID-19 cases on the prediction of turnover intentions. A Hosmer and Lemeshow Test (2000) indicated that the model was a good fit for the observed data, $\chi^{2}(8)=5.978, p=.650$. The overall model was a 
statistically significant improvement compared to the base model, $\chi^{2}(16)=93.838, p=.000$. The model explained approximately $15.4 \%$ (Nagelkerke $\left.R^{2}=.154\right)$ of the variance in turnover intention and correctly classified $75.1 \%$ of cases. Sensitivity was $12.2 \%$, specificity was $76.3 \%$, positive predictive value was $60.8 \%$, and negative predictive value was $22.4 \%$. Despite the statistical significance of the overall model, the COVID-19 cases variable did not significantly contribute to the prediction of turnover intention.

None of the job demands and resources were statistically significant predictors of turnover intention. However, consistent with the previous model, our analysis indicated that burnout was a statistically significant predictor of turnover intention among those who reported a "significant sense of burnout," $\chi^{2}(1)=16.526, p=.000$. The odds of those with a "significant sense of burnout" reporting an intent to leave their career was 8.315 times that of those with "little sense of burnout." Table 4 summarizes findings for the overall model.

\section{Qualitative Findings}

After analyzing our quantitative data, we analyzed the open-ended survey responses. We grouped our codes into two themes: work during a pandemic and personal life during a pandemic. We disaggregated our qualitative findings by the statistically significant quantitative variables to investigate how different variables were associated with our codes. This informed the presentation of our findings. Tables 5 and 6 are joint displays (Gutterman et al., 2015) with qualitative codes disaggregated by our outcome variables.

\section{Work During a Pandemic}

Respondents described ways that burnout manifested in their work and working conditions in four ways: additional work, working remotely, changes to teamwork, and changes 
to work quality. Although we expected responses to vary by the statistically significant quantitative variables, these codes were evenly distributed among quantitative categories.

Additional Work. For respondents, employment in higher education during a pandemic required work beyond typical job responsibilities. This key challenge was driven by multiple factors including reductions in staff, working online, and pandemic-related job tasks. When staff were reduced through furloughs, retirements, or position reductions, often they were not replaced because of hiring freezes. Therefore, "co-workers have had to [absorb] other duties" beyond their typical work expectations without additional staffing. Many respondents indicated working 70 to 80 hours per week, yet described how "it's never enough" to meet all the demands.

Many respondents discussed how the shift to remote work increased their workload. Working online allowed respondents to have more meetings, as they are easier to schedule online, but that left "little time during the day to get my own work done" leading to "more 10+ hour days" and "weekend work." Working from home also frequently eliminated boundaries between work and home, creating the sense that respondents were "now living at work." Exemplifying the perception of constant work, one respondent wrote that "As a manager said to me 'We are all working $24 / 7$ and it's expected."' This suggests that expectations of remote work were constant. This culture of continuous work had other negative impacts on employees outside of the workplace.

Respondents described new job tasks to manage COVID-19. Some front-line employees who worked on campus or responded to students' parents had particularly troublesome experiences. One respondent discussed how they had to navigate working with parents of students who felt that "the university caused this and should fix it" and had little care about the employee. HEPs frequently expressed concern about the constantly changing plans from 
institutional leadership. For example, one respondent described that they had "excessive overtime trying to meet the demands resulting from poor planning by upper administration." Generally, some respondents felt that "no one show[ed] appreciation for the work being done."

Additional work during a pandemic was not a surprising finding. However, among those increased workloads, respondents described troubling trends that made work in higher education largely unsustainable including additional work with fewer staff, working constantly online, and navigating changing directives from leadership. This indicates that institutions often did not prioritize employees as people, placing HEPs in untenable situations.

Remote Work. While remote work created additional work for employees, respondents described other ways that it impacted their jobs. Employees encountered technological issues such as the lack of stable internet connection or adequate technology. One respondent described how "no stipends are being offered to offset costs for technology" while others described how peers were furloughed until they could be provided appropriate technology. Finally, some participants described how remote work limited interactions with peers and students and their work was not as fulfilling as it was before. Online working conditions were often not fully supported by institutions to ensure employees' success, particularly during changing conditions. To respondents, institutions could have better supported employees to decrease this cause of burnout by ensuring all staff had adequate technology and maintaining clear expectations for using personal contact information.

Teamwork. The pandemic also influenced how employees collaborated. Frequently, respondents described how colleagues had "short temper[s]" or "more negativity and less creativity" in meetings and work. Working remotely removed informal opportunities for staff to "be together to commiserate and vent and brainstorm solutions." Individuals felt crunched for 
time and unable to have informal meetings. Occasionally, respondents described how interdepartmental collaboration was challenging, as they lacked strong interpersonal relationships. Although the qualitative responses that described collaboration were generally pessimistic, a few individuals noted how their teams collaborated effectively. One respondent wrote that their team was "still doing all they can to be kind to each other and help each other." While working collaboratively was generally a challenge during the pandemic, some teams recognized that many challenges were beyond their control.

Quality of Work. Working during a pandemic had an impact on the quality of work performed. Commonly, respondents described "small errors and mistakes," "decreased productivity," a harder time focusing on "more thought-heavy" tasks, or a "lack of interest in non-immediate projects." HEPs often reflected on their own change in work habits that led to changes in their performance.

Several respondents described how other people's work habits did not meet expectations. For example, one individual, who is one report removed from the chief executive, wrote that "many members of my team are not as engaged as they need to be in their work since they are working from home." Another respondent, lower in organizational hierarchy, shared that "staff have lost focus, not getting tasks done in a timely manner" and "not realizing that work hours need to be adhered to." These perspectives highlight how work expectations may not have adjusted to account for the pandemic's role in HEPs' lives.

\section{Personal Life During a Pandemic}

Respondents discussed how suffering from burnout during a pandemic impacted their personal lives, including their emotional and mental health. 
Emotional and Mental Health. Over half of respondents described some mental or emotional symptoms of burnout. Frequently, respondents expressed feelings of anxiety, fatigue, depression, exhaustion, and low morale. Remote work played a role in HEPs' emotional stress suggesting that "the stress of work is mixed with the stress of home life." Many respondents expressed how the length of the pandemic was challenging and has led to "feeling depressed each day because things aren't getting better in the world." The stress of working during the pandemic also led some HEPs and their colleagues to "have weekly mini breakdowns where we just cry."

While these manifestations of mental health struggles were common, some respondents also discussed their feelings toward higher education, occasionally planning to leave the field completely. Typical of these responses was "pessimism about the future of higher education" and feelings of being "grossly abused as a human resource." HEPs' pessimism about the future of their field or their organization's lack of care for their well-being may negatively impact their productivity, ability to navigate the pandemic, and future career plans.

Personal Life. Respondents shared how their personal lives were upturned. Often, respondents described "struggling to get out of bed in the morning." Sometimes respondents were "made to feel guilt just for taking one day off," while others were "not given a weekend to refresh their mental and emotional health." HEPs noted how they were required to work on urgent projects on vacation days. When HEPs would take time off, they felt that "time off = more catch-up" once they returned to work.

Respondents frequently described challenges related to childcare and parenting. Multiple individuals described contradictory expectations from their employer and their child's school, especially as grace provided early in the pandemic was not extended for its duration. One parent 
wrote that "being required to return to a face-to-face setting disallowed me to keep my child home to pursue remote learning" and that they "maintained the responsibilities of my position...with great detriment to my emotional and physical health." Even parents who were not required to return to campus described the unique burdens they faced. One respondent wrote that “As a parent having to remote teach my children and keep up with work has not been easy and the demand from my institution to prove how hard I work is frustrating." This HEP had not only to care for children, but also "prove" how hard they work. This disconnect between expectations for K-12 schooling and the higher education workplace was particularly problematic for caretakers.

Although many experiences surrounding the personal impacts of working during a pandemic focused on childcare and mental health, we noted several other important trends. Multiple respondents noted that their physical health was negatively affected including "higher blood pressure" and returning to or being prescribed anxiety medication. Respondents noted that they did not have "the energy or motivation to participate in leisure activities, hobbies" to relieve stress.

\section{Mixed Methods Findings}

It is important to note where our quantitative and qualitative findings diverged. Staffing level changes and transition of services were statistically significant predictors in at least one of our regression models. However, our qualitative analyses found that these variables did not have differences in the quantity of codes that reflect each of these variables.

One construct that was meaningful in the qualitative analysis and statistically significant in some of our models was one's organizational proximity to the chief executive. However, these constructs were operationalized differently. The quantitative measure indicated the number of 
supervisors between an employee and chief executive, while the qualitative measure captured how respondents' positions within the organization influenced their experience, including feeling ignored or having support for their direct reports. These different operationalizations highlight the varied ways that organizational hierarchy matters for HEPs. One middle manager shared that “executive leadership does not share the concerns and fears of my front-line workers." HEPs in positions at lower levels of an organizational hierarchy expressed concerns about how senior staff managed the institutional response to the pandemic. One typical response included that "senior staff has not recognized these increased workloads and lack of resources." Even when these supervisors noticed their hard work, some respondents noted that supervisors did "nothing to address burnout." When respondents discussed lower-level employees, they were often framed as a concern. For example, one manager instituted daily check-ins and when staff were just "saying what they think we want to hear, but are not producing results," they followed up with staff members individually to provide support. However, this generosity towards HEPs was not uniform. Some described how employees "[pushed] back on standard functions of [the] job" or had "poor time management and too many distractions when working from home." Although these respondents expressed concerns about their fellow employees' productivity, the tone of some respondents did not consider the personal lives of colleagues.

\section{Discussion \& Conclusion}

During the pandemic, HEPs faced unprecedented changes to their work to keep communities, employees, and students safe. Our mixed-methods analysis indicated that these work environments were challenging in multiple ways.

First, our quantitative findings reaffirm that findings of previous research on burnout and turnover in higher education remain relevant during the pandemic. We find that individuals who 
were able to transition to remote work without significant disruption had decreased odds of burnout. Through the JD-R framework (Demerouti et al., 2001), a difficult transition to remote work is a job demand associated with increased burnout. Although AACRAO's survey was not explicitly designed with the JD-R framework, our study contributes to recent literature using JDR to understand how high job demands are associated with burnout among HEPs (e.g., KunkCzaplicki, 2021, Mudrak et al., 2018). While productivity may have decreased for HEPs working remotely, our evidence shows that decreased burnout associated with a seamless transition to remote work may improve employee retention. We find that significant levels of burnout are a predictor of HEPs' increased turnover intentions, reaffirming prior research (Mullen, Malone, et al., 2018). Thus, burnout before and during the pandemic may be similar enough for institutional leaders to plan responses to improve the working conditions of HEPs using earlier scholarship.

Second, our qualitative findings illuminated common reasons for burnout. These included expectations of additional work and constant availability. These findings are not new to higher education, as similar working conditions in the field led to burnout, fatigue, and departure (Marshall et al., 2016; Mullen, Malone, et al., 2018; Wilk, 2016). However, many previous studies of the higher education workforce study one segment of the organizational hierarchy, such as entry-level employees or middle managers. Our data include a cross section of the organizational hierarchy and show that one's location in the organizational hierarchy informs perceptions of organizational responses to working conditions, like prior research on furloughs (Pelletier et al., 2015). We recommend future research continue to examine how one's position within an organization informs perceptions of working conditions.

Our qualitative findings highlighted many job demands placed on HEPs during COVID19. Less apparent were resources to address challenging conditions. Although some respondents 
described team-level support structures, these resources were not common. Instead, when HEPs described job resources, they emphasized the lack of resources like adequate technology or meaningful time off. Institutions should develop and widely disseminate comprehensive remote work policies that delineate expectations and clearly identify the resources available to support employees. As work-from-home and flexible work arrangements become increasingly commonplace, such policies may be critical to the recruitment and retention of HEPs (Ellis, 2021b). Institutions can also prioritize employee mental health through campus-wide wellness days and similar initiatives for all students and staff (Chawla, 2020).

Finally, we share recommendations about how future research can draw upon our findings. Our mixed methods approach allowed us to capture challenges of working during the pandemic that were not accounted for in the close-ended survey items including decreased productivity and mental and emotional health challenges of HEPs. Instead of adapting our findings into new quantitative questions, we encourage researchers and institutional agents to utilize the strengths of mixed methods research by using open-ended items. Qualitative data can highlight unique challenges that inform campus-specific solutions based on an institution's mission, characteristics, culture, and assets.

Respondents also noted that institutions were occasionally aware of challenges but did not change practices. Therefore, institutional research on workplace conditions should include plans to enact change to support employees, not just collect data. Our qualitative findings emphasized the additional burdens on parents, a commonality with other COVID-19 research (e.g., Calarco et al., 2021; Power, 2020). Recent research has found that children of HEPs internalize their parent's bad days at work (Lehman \& Krebs, 2018). Therefore, future 
researchers should consider how HEP workplace conditions amid the pandemic may have affected parenting HEPs and their children.

Since respondents completed AACRAO’s October 2020 survey, COVID-19 vaccines have been developed and are widely available in the United States. Most college campuses have returned to in-person instruction and HEPs are largely back on campus. Yet, COVID-19 cases on college campuses are higher than when our data were collected (New York Times, 2021). As such, our calls for practices that center the humanity of all HEPs and systemic changes to address burnout (Peterson, 2020; Squire \& Nicolazzo, 2019) may be more dire than our evidence shows. HEPs have increasingly vocalized concerns about practices that emphasize institutional finances instead of their health and work-life balance (Ellis, 2021a). Higher education institutions may be on the precipice of high rates of turnover because of growing discontent with workplace conditions (Ellis, 2021b). College and universities must adjust practices that burn through HEPs (Anderson, 2021) and instead prioritize the humanity of their workforce by making institutionallevel reforms to effectively navigate the challenges to come. 


\section{References}

Alvarez, R. M., Atkenson, L. R., Levin, I., \& Li, Y. (2019). Paying attention to inattentive survey respondents. Political Analysis, 27(2), 145-162. https://doi.org/10.1017/pan.2018.57

American Association of Collegiate Registrars and Admissions Officers (AACRAO). (n.d.). 2018 demographics. https://www.aacrao.org/who-we-are/mission-visionvalues/demographics/2018-demographics

Anderson, R. K., (2021). Burned out or burned through?: The costs of student affairs diversity work. Journal of Student Affairs Research and Practice, 58(4), 359-371. https://doi.org/10.1080/19496591.2020.1822853

Bauman, D. (2021). Here's who was hit hardest by higher ed's pandemic-driven job losses. The Chronicle of Higher Education. https://www.chronicle.com/article/heres-who-was-hithardest-by-higher-eds-pandemic-driven-job-losses

Bazeley, P. (2009). Integrating data analysis in mixed methods research. Journal of Mixed Methods Research, 3(3), 203-207. https://doi.org/10.1177/1558689809334443

Berger, R. (2015). Now I see it, now I don't: Researcher position and reflexivity in qualitative research. Qualitative Research, 15(2), 219-234.

https://doi.org/10.1177/1468794112468475

Box, G. E. P., \& Tidwell, P. W. (1962). Transformation of the independent variables. Technometrics, 4, 531-550. 
Brewer, E. W., \& Clippard, L. F. (2002). Burnout and job satisfaction among student support services personnel. Human Resource Development Quarterly, 13(2), 169-186. https://doi.org/10.1002/hrdq.1022

Calarco, J. M., Meanwell, E., Anderson, E. M., \& Knopf, A. S. (2021). By default: How mothers in different-sex dual-earner couples account for inequalities in pandemic parenting. Socius, 7, 1-15. https://doi.org/10.1177/23780231211038783

Chawla, S. (2020, April 7). Provide holistic mental health and wellbeing support for your faculty and staff during COVID-19. EAB. https://eab.com/insights/expertinsight/strategy/mental-health-wellbeing-faculty-staff-covid-19

Chessman, H. M. (2021). Student affairs professionals, well-being, and work quality. Journal of Student Affairs Research and Practice, 58(2), 148-162. https://doi.org/10.1080/19496591.2020.1853556

Chronicle of Higher Education. (2020). As COVID-19 pummels budgets, colleges are resorting to layoffs and furloughs: Here's the latest. https://www.chronicle.com/article/weretracking-employees-laid-off-or-furloughed-by-colleges

Creswell, J. W., \& Plano Clark, V. L. (2018). Designing and conducting mixed methods research. (3rd). Sage Publications.

Dahlvig, J. E., \& Beers, S. (2018). The status of student affairs divisions within the CCCU. Christian Higher Education, 17(4), 215-239. https://doi.org/10.1080/15363759.2018.1460883 
Demerouti, E., \& Bakker, A. B. (2011). The job demands-resources model: Challenges for future research. SA Journal of Industrial Psychology/SA Tydskrif vir Bedryfsielkunde, 37(2), Article \#974. https://doi.org/10.4102/sajip.v37i2.974

Demerouti, E., Bakker, A. B., Nachreiner, F., \& Schaufeli, W. B. (2001). The job demandsresources model of burnout. Journal of Applied Psychology, 86(3), 499-512. https://doi.org/10.1037/0021-9010.86.3.499

Ellis, L. (2021a, June 17). The great disillusionment. The Chronicle of Higher Education. https://www.chronicle.com/article/the-great-disillusionment

Ellis, L. (2021b, June 17). ‘A mass Exodus': Inflexible remote-work policies could bring major staff turnover. The Chronicle of Higher Education. https:/www.chronicle.com/article/amass-exodus-inflexible-remote-work-policies-may-bring-major-staff-turnover-forcolleges

Gracia, N. J. (2020). COVID-19's disproportionate impact on communities of color spotlights the nation's systemic inequities. Journal of Public Health Management and Practice, 26(6), 518-521. https://doi.org/10.1097/PHH.0000000000001212

Gutterman, T. C., Fetters, M. D., \& Creswell, J. W. (2015). Integrating quantitative and qualitative results in health science mixed methods research through joint displays. Annals of Family Medicine, 13(6), 554-561. https://doi.org/10.1370/afm.1865

Hosmer, D. W., Jr., \& Lemeshow, S. (2000). Applied logistic regression (2nd Ed.). John Wiley \& Sons. 
Howard-Hamilton, M. F., Palmer, C., Johnson, S., \& Kicklighter, M. (1998). Burnout and related factors: Differences between women and men in student affairs. College Student Affairs Journal, 17(2), 80-91.

Kaleba, N. (2021). Staff survey highlights interest in remote work, other concerns. The University Record. https://record.umich.edu/articles/staff-survey-highlights-interest-inremote-work-other-concerns

Keith, T. Z. (2015). Multiple regression and beyond: An introduction to multiple regression and structural equation modeling. (2nd ed). Routledge.

Kilgore, W. (2020). Impacts of 2020 Disruptions on Work and Career Survey. American Association of Collegiate Registrars and Admissions Officers.

Kunk-Czaplicki, J. A. (2021). A quantitative investigation of job demands, job resources, and exposure to trauma on burnout in certain student affairs professionals [Doctoral dissertation, Bowling Green State University], OhioLink Electronic Theses and Dissertations Center. http://rave.ohiolink.edu/etdc/view?acc_num=bgsu1629829020316752

Lehman, J., \& Krebs, S. R. (2018). My father works with carpet, my mother works with emotion: Understanding the lived experiences of children of student affairs professionals. NASPA Journal About Women in Higher Education, 11(3), 284-296. https://doi.org/10.1080/19407882.2018.1425145

Li, P., \& Guthrie, J. P. (2015). Survivor syndrome. Wiley Encyclopedia of Management. 11, 1-2. https://doi.org/10.1002/9781118785317.weom110027 
Liu, X., \& Koirala, H. (2012). Ordinal regression analysis: Using generalized ordinal logistic regression models to estimate educational data. Journal of Modern Applied Statistical Methods, 11(1), 21. https://doi.org/10.22237/jmasm/1335846000

Marinoni, G., van't Land, H., \& Jensen, T. (2020). The impact of COVID-19 on higher education around the world: IAU Global survey report. International Association of Universities. https://www.iauaiu.net/IMG/pdf/iau_covid19_and_he_survey_report_final_may_2020.pdf

Marshall, S. M., Gardner, M. M., Hughes, C., \& Lowery, U. (2016), Attrition from student affairs: Perspectives from those who exited the profession. Journal of Student Affairs Research and Practice, 53(2), 146-159. https://doi.org/10.1080/19496591.2016.1147359

Maslach, C. (2003). Burnout: The cost of caring. Malor Books.

McClure, K. R. (2020, August 14). Burnout is coming to campus. Are college leaders ready?. Edsurge. https://www.edsurge.com/news/2020-08-14-burnout-is-coming-tocampus-are-college-leaders-ready

McGraw, D., Hubler, S., \& Levin, D. (2020). As the virus deepens financial trouble, colleges turn to layoffs. The New York Times. https://www.nytimes.com/2020/07/16/us/coronavirus-college-faculty-layoffs.html

Mellieon, Jr, H. I., \& Robinson, A. P. (2021). The new norm: Faculty perceptions of condensed online learning. American Journal of Distance Education,35(3), 170-183. https://doi.org/10.1080/08923647.2020.1847626 
Molock, S. D., \& Parchem, B. (2021). The impact of COVID-19 on college students from communities of color. Journal of American College Health, Advance Online Publication. https://doi.org/10.1080/07448481.2020.1865380

Mudrak, J., Zabrodska, K., Kveton, P., Jelinek, M., Blatny, M., Solcova, I., \& Machovcova, K. (2018). Occupational well-being among university faculty: A job demands-resources model. Research in Higher Education, 59(3), 325-348. https://doi.org/10.1007/s11162017-9467-x

Mullen, P. R., Blount, A. J., Lambie, G. W., \& Chae, N. (2018). School counselors' perceived stress, burnout, and job satisfaction. Professional School Counseling, 21(1), 1-10. https://doi.org/10.1177/2156759X18782468

Mullen, P. R., Malone, A., Denney, A., \& Dietz, S. S. (2018). Job stress, burnout, job satisfaction, and turnover intention among student affairs professionals. College Student Affairs Journal, 36(1), 94-108. https://doi.org/10.1353/csj.2018.0006

New York Times. (2021). Coronavirus (Covid-19) data in the United States [Data set]. Retrieved July 7, 2021 from https://github.com/nytimes/covid-19-data

O’Connell, M., \& Kung, M. (2007). The cost of employee turnover. Industrial Management, 49(1), 14-19.

Pelletier, K. L., Kottke, J. L., \& Reza, E. M. (2015). During furloughs, who is more attached to a public university? Staff? Faculty?...Managers. Public Personnel Management, 44(1), 120-142. https://doi.org/10.1177/0091026014558155 
Peterson, A. H. (2020). Can't even: How millennials became the burnout generation. Houghton Mifflin Harcourt Publishing Company.

Power, K. (2020). The COVID-19 pandemic has increased the care burden of women and families. Sustainability: Science, Practice and Policy, 16(1), 67-73. https://doi.org/10.1080/15487733.2020.1776561

Preston, P. J., Peterson, H., Sanchez, D., Carlos, A. C., \& Reed, A. (2021). Serving students takes a toll: Self-care, health, and professional quality of life. Journal of Student Affairs Research and Practice, 58(2), 163-178. https://doi.org/10.1080/19496591.2020.1853558

Rapanta, C., Botturi, L., Goodyear, P., Guàrdia, L., \& Koole, M. (2020). Online university teaching during and after the Covid-19 crisis: Refocusing teacher presence and learning activity. Postdigital Science and Education, 2(3), 923-945. https://doi.org/10.1007/s42438-020-00155-y

Regehr, C., \& Goel, V. (2020). Managing COVID-19 in a large urban research-intensive university. Journal of Loss and Trauma, 25(6-7), 523-539. https://doi.org/10.1080/15325024.2020.1771846

Romano, C. R., Hanish, J., Phillips, C., \& Waggoner, M. D. (2010). The new normal: Senior student affairs officers speak out about budget cutting. New Directions for Student Services, 129, 59-70. https://doi.org/10.1002/ss.351

Rosser, V. J., \& Townsend, B. K. (2006). Determining public two-year faculty's intent to leave: An empirical model. Journal of Higher Education, 77(1), 124-147. https://doi.org/10.1080/00221546.2006.11778921 
Ryan, G. W., \& Bernard, H. R. (2003). Techniques to identify themes. Field Methods, 15(1), 85109. https://doi.org/10.1177/152822X02239569

Saldaña, J. (2013). The coding manual for qualitative researchers (2nd ed). Sage.

Schaufeli, W. B., Leiter, M. P., \& Maslach, C. (2009). Burnout: 35 years of research and practice. Career Development International, 14(3), 204-220. https://doi.org/10.1108/13620430910966406

Shenton, A. K. (2004). Strategies for ensuring trustworthiness in qualitative research projects. Education for Information, 22(2), 63-75. https://doi.org/10.3233/EFI-2004-22201

Squire, D. D., \& Nicolazzo, Z. (2019). Love my naps, but stay woke: The case against self-care. About Campus: Enriching the Student Learning Experience, 24(2), 4-11. https://doi.org/10.1177/1086482219869997

Son, C., Hegde, S., Smith, A., Wang, X., \& Sasangohar, F. (2020). Effects of COVID-19 on college students' mental health in the United States: Interview survey study. Journal of Medical Internet Research, 22(9), e21279. https://doi.org/10.2196/21279

Steele, T. (2018). Toxicity in the work environment: Retaining staff members of color at a predominantly white institution. College Student Affairs Journal, 36(1), 109-123. https://doi.org/10.1353/csj.2018.0007

Stevens, J. P. (2002). Applied multivariate statistics for the social sciences (Vol. 4). Erlbaum.

Szekeres, J. (2006). General staff experiences in the corporate university. Journal of Higher Education Policy and Management, 28(2), 1330145. https://doi.org/10.1080/13600800600750962 
Turk, J. M., Soler, M. C., \& Vigil, D. (2020). College and university presidents respond to COVID-19: April 2020 survey. American Council on Education. https://www.acenet.edu/Documents/Presidents-Respond-COVID19-April2020.pdf

U.S. Department of Education. (2019). National Center for Education Statistics, Integrated Postsecondary Education Data System (IPEDS), [Survey Year 2019], [Survey Components: Institutional Characteristics, Fall Enrollment, Fall Staff].

Wilk, K. E. (2016). Work-life balance and ideal worker expectations for administrators. New Directions for Higher Education, 176, 37-51. https://doi.org/10.1002/he.20208

World Health Organization (2021). International statistical classification of diseases and related health problems (1 $11^{\text {th }}$ ed.). https://icd.who.int 
Table 1. Descriptive Statistics of Survey Responses

\section{$n$}

Organizational proximity to chief executive

Chief executive

One report

Two reports

Three or more reports

Front-line student service

Provides front-line student service

Does not provide front-line student service

Transition of functions and services

Remote work transitioned with little disruption

Remote work unable to be transitioned/not transitioned

Staffing level change

All staff kept fully employed

\section{Burnout}

Little to no sense of burnout; no concerns about the pace of future work

Slight sense of burnout; no concerns about the pace of future work

Some sense of burnout; some concern about the pace of future work

Definite sense of burnout; concerned about the pace of future work

Significant sense of burnout; significant concern about the pace of future work

Turnover intention
6.0 


\section{Table 2.}

Descriptive Statistics of the Institutions Represented by the Survey Respondents

\begin{tabular}{lcc}
\hline & $n$ & Percentage \\
\hline FTE enrollment headcount & 272 & 25.2 \\
$28-2,000$ & 431 & 39.9 \\
$2,001-10,000$ & 130 & 12.0 \\
$10,001-18,000$ & 247 & 22.9 \\
18,001 or more & & \\
& & 30.7 \\
FTE staff & 332 & 35.6 \\
$6-500$ & 385 & 20.7 \\
$501-2,000$ & 224 & 12.9 \\
$2,001-7,000$ & 139 & \\
$7,001-$ or more & & 57.7 \\
Institutional level & & \\
Four or more years & & \\
Less than four years & & 48.9 \\
Private & 552 & \\
\hline
\end{tabular}


Table 3. Summary of Job Resources and Demands as Predictors of Burnout

\begin{tabular}{|c|c|c|}
\hline & Model 1 & Model 2 \\
\hline & $\begin{array}{l}\text { Odds Ratio } \\
\text { (SE) }\end{array}$ & $\begin{array}{l}\text { Odds Ratio } \\
\text { (SE) }\end{array}$ \\
\hline \multicolumn{3}{|l|}{ Organizational proximity } \\
\hline Chief executive & $\begin{array}{l}0.614^{*} \\
(0.245)\end{array}$ & $\begin{array}{c}0.658 \\
(0.315)\end{array}$ \\
\hline One report & $\begin{array}{c}0.978 \\
(0.138)\end{array}$ & $\begin{array}{l}1.008 \\
(0.162)\end{array}$ \\
\hline Three or more reports & $\begin{array}{c}1.185 \\
(0.149)\end{array}$ & $\begin{array}{l}1.260 \\
(0.164)\end{array}$ \\
\hline Provides front-line student service & $\begin{array}{c}0.820 \\
(0.178)\end{array}$ & $\begin{array}{c}0.680 \\
(0.208)\end{array}$ \\
\hline \multicolumn{3}{|l|}{ Transition of functions and services } \\
\hline $\begin{array}{l}\text { Remote work transitioned with significant } \\
\text { disruption } \\
\text { Remote work unable to be transitioned/not } \\
\text { transitioned }\end{array}$ & $\begin{array}{l}1.713^{* *} \\
(0.142) \\
1.751^{* *} \\
(0.143)\end{array}$ & $\begin{array}{l}1.971^{* *} \\
(0.164) \\
1.745^{* *} \\
(0.166)\end{array}$ \\
\hline \multicolumn{3}{|l|}{ Staffing level change } \\
\hline Some staff had reduced hours/were furloughed & $\begin{array}{c}1.247 \\
(0.159)\end{array}$ & $\begin{array}{c}1.245 \\
(0.180)\end{array}$ \\
\hline Some staff positions were eliminated & $\begin{array}{c}1.342 \\
(0.157)\end{array}$ & $\begin{array}{c}1.251 \\
(0.184)\end{array}$ \\
\hline Institutional control: private & $\begin{array}{c}1.028 \\
(0.122)\end{array}$ & $\begin{array}{c}0.977 \\
(0.141)\end{array}$ \\
\hline Institutional level: less than four years & $\begin{array}{c}0.910 \\
(0.183)\end{array}$ & $(0.382)$ \\
\hline FTE student to staff ratio & $\begin{array}{c}1.001 \\
(0.002)\end{array}$ & $\begin{array}{l}1.000 \\
(0.002)\end{array}$ \\
\hline COVID-19 cases, logged & & $\begin{array}{c}0.958 \\
(0.036)\end{array}$ \\
\hline $\begin{array}{l}n \\
\text { Nagelkerke } R^{2}\end{array}$ & $\begin{array}{l}1,080 \\
0.035\end{array}$ & $\begin{array}{c}830 \\
0.048\end{array}$ \\
\hline
\end{tabular}

Note. $S E=$ standard error. ${ }^{* *} p<0.01,{ }^{*} p<0.05$. Reference categories: organizational proximity: two reports; front-line student service: does not provide front-line student service; transition of functions and services: remote work transitioned with little disruption; staffing level change: all staff kept fully employed; institutional control: public; institutional level: four or more years. 
Table 4. Summary of Job Resources and Demands and Burnout as Predictors of Turnover Intentions

\section{Model 1}

Odds Ratio

(SE)

Organizational proximity

Chief executive

One report

Three or more reports

Provides front-line student service

Transition of functions and services

Remote work transitioned with significant disruption

Remote work unable to be transitioned/not transitioned

Staffing level change

Some staff had reduced hours/were furloughed

Some staff positions were eliminated

Institutional control: private

Institutional level: Less than four years

FTE Student to staff ratio

Slight sense of burnout, no concern

Some sense of burnout; some concern

Definite sense of burnout; concerned

Significant burnout, significant concern

COVID-19 cases, logged

$\begin{array}{cc}1.122 & 0.651 \\ (0.323) & (0.384) \\ 1.238 & 0.590 \\ (0.178) & (0.402) \\ 0.893 & 0.633 \\ (0.196) & (0.387) \\ 1.399 & 0.800 \\ (0.227) & (0.271)\end{array}$

$\begin{array}{cc}1.301 & 0.817 \\ (0.177) & (0.251) \\ 1.043 & 0.843 \\ (0.183) & (0.206)\end{array}$

1.018

1.464

(0.206)

$1.713 * *$

$(0.293)$

$(0.191)$

0.983

0.738

(0.233)

(0.160)

1.238

1.158

(0.238)

1.000

(0.002)

(0.184)

1.476

(0.434)

1.337

(0.489)

0.998

(0.003)

1.012

(0.546)

2.004

1.403

(0.414)

(0.524)

$3.221 * *$

2.179

(0.398)

(0.507)

$11.035^{* *}$

$8.315^{* *}$

(0.415)
(0.521)

0.940

(0.046)

0.334

(0.805)

1,080

0.155
830

0.154

Nagelkerke $R^{2}$

Note. $S E=$ standard error. $* * p<0.01, * p<0.05$. Reference categories: organizational proximity: two reports; front-line student service: does not provide front-line student service; transition of functions and services: remote work transitioned with little disruption; staffing level change: all staff kept fully employed; institutional control: public; institutional level: four or more years. 
Table 5. Joint display of qualitative themes, disaggregated by burnout levels

\begin{tabular}{ccccccc}
\hline & $\begin{array}{c}\text { Little } \\
\text { Sense }\end{array}$ & $\begin{array}{c}\text { Slight } \\
\text { sense }\end{array}$ & $\begin{array}{c}\text { Some } \\
\text { sense }\end{array}$ & $\begin{array}{c}\text { Definite } \\
\text { sense }\end{array}$ & $\begin{array}{c}\text { Significant } \\
\text { sense }\end{array}$ & Overall \\
& $n=65$ & $n=183$ & $n=235$ & $n=420$ & $n=177$ & $n=1,080$ \\
\hline Working in a pandemic & & & & & & \\
Additional work & 2 & 31 & 45 & 111 & 49 & 238 \\
& $(3.1 \%)$ & $(16.9 \%)$ & $(19.1 \%)$ & $(26.4 \%)$ & $(27.7 \%)$ & $(22 \%)$ \\
Collaboration & 2 & 22 & 38 & 76 & 35 & 173 \\
Impacts on work & $(3.1 \%)$ & $(12 \%)$ & $(16.2 \%)$ & $(18.1 \%)$ & $(19.8 \%)$ & $(16 \%)$ \\
quality & 1 & 19 & 35 & 73 & 27 & 155 \\
Organizational & $(1.5 \%)$ & $(10.4 \%)$ & $(14.9 \%)$ & $(17.4 \%)$ & $(15.3 \%)$ & $(14.4 \%)$ \\
hierarchy* & 5 & 26 & 29 & 73 & 47 & 180 \\
Remote work concerns & $(7.7 \%)$ & $(14.2 \%)$ & $(12.3 \%)$ & $(17.4 \%)$ & $(26.6 \%)$ & $(16.7 \%)$ \\
& $(13.8 \%)$ & 22 & 29 & 66 & 24 & 150 \\
Staffing level change* & 10 & 38 & $(12.3 \%)$ & $(15.7 \%)$ & $(13.6 \%)$ & $(13.9 \%)$ \\
& $(15.4 \%)$ & $(20.8 \%)$ & $(18.3 \%)$ & $(20.2 \%)$ & $(26 \%)$ & $(20.6 \%)$ \\
Personal life in a pandemic & & & & & & \\
& & & & & & \\
Concerns about future & 3 & 15 & 17 & 36 & 18 & 89 \\
Emotional \& mental & $(4.6 \%)$ & $(8.2 \%)$ & $(7.2 \%)$ & $(8.6 \%)$ & $(10.2 \%)$ & $(8.2 \%)$ \\
health & 12 & 78 & 113 & 239 & 117 & 559 \\
& $(18.5 \%)$ & $(42.6 \%)$ & $(48.1 \%)$ & $(56.9 \%)$ & $(66.1 \%)$ & $(51.8 \%)$ \\
Personal life & 5 & 37 & 45 & 115 & 57 & 259 \\
& $(7.7 \%)$ & $(20.2 \%)$ & $(19.1 \%)$ & $(27.4 \%)$ & $(32.2 \%)$ & $(24 \%)$ \\
\hline
\end{tabular}

Note. Percentages are column percentages. Codes with asterisks $(*)$ represent a priori codes. 
Table 6. Joint display of qualitative themes, disaggregated by increased turnover intention

\begin{tabular}{lccc}
\hline & Yes & No & Overall \\
& $n=317$ & $n=763$ & $n=1,080$ \\
\hline Working in a pandemic & & & \\
Additional work & 66 & 172 & 238 \\
& $(20.8 \%)$ & $(22.5 \%)$ & $(22 \%)$ \\
Impacts on work quality & 44 & 111 & 155 \\
& $(13.9 \%)$ & $(14.5 \%)$ & $(14.4 \%)$ \\
Collaboration & 61 & 112 & 173 \\
Organizational & $(19.2 \%)$ & $(14.7 \%)$ & $(16 \%)$ \\
hierarchy* & 74 & 106 & 180 \\
Remote work concerns & $(23.3 \%)$ & $(13.9 \%)$ & $(16.7 \%)$ \\
& 43 & 107 & 150 \\
Staffing level change* & $(13.6 \%)$ & $(14 \%)$ & $(13.9 \%)$ \\
& 79 & 143 & 222 \\
Personal life in a pandemic & $(24.9 \%)$ & $(18.7 \%)$ & $(20.6 \%)$ \\
& & & \\
Concerns about future & & & \\
Emotional \& mental & 31 & 58 & 89 \\
health & $(9.8 \%)$ & $(7.6 \%)$ & $(8.2 \%)$ \\
Personal lives & 188 & 371 & 559 \\
& $(59.3 \%)$ & $(48.6 \%)$ & $(51.8 \%)$ \\
\hline
\end{tabular}

Note. Percentages are column percentages. Codes with asterisks $\left(^{*}\right)$ represent a priori codes. 